\title{
Study on the Development Path of Public Service System for the Disabled with Chinese Characteristics
}

\author{
Qing Dong ${ }^{1, *} \mathrm{Na} \mathrm{Yu}^{2}$
}

\author{
${ }^{1}$ School of Public Administration, Zhongnan University of Economics and Law, Wuhan, Hubei 430073, China \\ ${ }^{2}$ Enshi Municipal Health Bureau of Hubei Province, Enshi, Hubei 445000, China \\ *Corresponding author.Email: 173812982@qq.com
}

\begin{abstract}
China, now in the transitional stage of comprehensively deepening reform, has witnessed new normal in its economic and social development. Accordingly, the understanding the Chinese characteristics of public service for the disabled objectively and accurately based on previous experience and lessons to highlight its edge and features is worth attention as for the development path of the cause of the disabled. Starting from the evolution of public service for the disabled since the founding of the People's Republic of China, the paper covers theoretical path, organizational path and institutional path of the service system logically, analyzing the Chinese characteristics reflected in the above three paths and systematically expounds the development path of public service system for the disabled in China.
\end{abstract}

Keywords: Chinese characteristics, public service for the disabled, theoretical path, organization path, institutional path

\section{INTRODUCTION}

The disabled shares as long a history as human being, which is an inevitable social price to be paid in the evolution of human society. [1] Thoughts on security for the disabled appeared as early as ancient times in China, one of the four ancient civilizations. Confucius' insight on security for the disabled can be found in Li Yun History of Propriety of Book of Rites: 使老有所终, 壮有所用, 幼有所长, 弱、鿒、孤、独、废疾者皆 有所养 (The elderly can live out their days, the middleaged can realize their value, the young can be raised healthy and happily, the widowed, the helpless, the disabled and the sick are guaranteed). [2] The public service for the disabled of a country mirrors its service and civilization to a certain extent. As the group that suffers for social development, the disabled should and must enjoy due respect from the whole society and public service from the government in the evolution of human society. Public service system for the disabled has been initially established in China, providing services such as disability prevention and rehabilitation, education, employment, culture and sports, and barrierfree environment construction for the disabled, which has significantly improved their living and development conditions and enhanced their social participation. Study on development path of public service for the disabled with Chinese characteristics contributes to the objective retrospect of the development of the cause of the disabled, as well as the top-level design of the cause.

\section{THE EVOLUTION STAGE OF PUBLIC SERVICE FOR THE DISABLED IN CHINA}

As for the history of the development of the cause of the disabled in China, this paper holds that the development of public service for the disabled has gone through four stages since the founding of the People's Republic of China.

First, the period before the reform and opening up, from 1949 to 1977 , represented by the founding of the People's Republic of China. Public understanding towards the disabled then was backward. The disabled were excluded from the group of "people". The general public holds that the disabled are "maimed person" and should be abandoned. Due to the unfavorable economic and social landscape in China then, only essential living materials can be guaranteed for the disabled. According to Interim Regulations on Preferential Treatment and Compensation of Revolutionary Disabled Army Men released in 1950, the disability evaluation of revolutionary disabled army men shall be determined by the severity of their disability and the degree of incapacity. [3] The concepts of "a person who is maimed by a glorious wound in struggle against the enemy" and "a person who is crippled as a result of a work-related injury" can be found in Provisional Regulations on Compensation for Casualties of Revolutionary Personnel. [4] What's more, the notion of certificate of invalidity for militia and civil workers 
is launched in Interim Regulations on Compensation for Injuries and Casualties of Militia and Civil Workers. [5] Detailed regulations on disability pension for revolutionary army man, workers, militia and civil workers are mentioned in the above three documents, which indirectly shapes public awareness towards "disabled people". Report on Urban Relief and Welfare in 1951 proposed that necessary assistance shall be given to the disabled poor who are incapacitated for work. Regulations of the People's Republic of China on Labor Insurance in 1951 detailed measures for workers to receive material assistance after being disabled. [6] The year 1953 witnessed the establishment of Chinese Association for the Welfare of the Blind in Beijing and the publication of Monthly for the Blind, an official magazine, named by Chairman Mao Zedong. 1956 saw the founding of Chinese Association for the Welfare of the Deaf in Beijing. In 1960, Chinese Association for the Welfare of the Blind and of the Deaf were merged into China Association for the Blind and Deaf. China Association for the Blind and Deaf basically suspended work from 1966 to 1977 as the staff were sent to work on the Cenhe farm in Shashi city, Hubei province due to the "Cultural Revolution". [7]

The second is the span from 1978 to 2005 marked by the convening of the third Plenary Session of the 11th CPC Central Committee, which is critical for the development of the public service for the disabled. Thanks to socialist humanitarianism, public service for the disabled in China at this stage is emerging. In 1980, Notice on the Payment of Income Tax by Welfare Production Units Organized by Civil Affairs Departments jointly launched by Ministry of Finance and Ministry of Civil Affairs stipulates that "welfare production units where blind, deaf, dumb and disabled persons account for more than $35 \%$ of the total personnel are exempt from income tax; welfare production units where blind, deaf, dumb and disabled persons account for more than $10 \%$ but less than $35 \%$ of the total personnel shall pay income tax in half." [8] China Foundation for Disabled Persons (CFDP) was established in Beijing in 1984. In the same year, the paralympic sports team was sent by China for the first time to participate in World Paralympic Games in New York. A total of 24 athletes broke world record nine times and notched up 24 medals, including two golds. In 1987, China National Radio and China Central Television (CCTV) jointly launched a special program on the life of the disabled. In the same year, sample survey of disabled people was first carried out in China, based on which it's estimated that the disabled amounts to 51.64 million in China. [9] In 1988, China Disabled Persons' Federation (CDPF) was established, and Fiveyear Work Program for the Disabled in China (19881992) was issued. In August 1991, the first barrier-free road for blind people in China was finished: the blind track of LanDianChang, HaiDian district, Beijing. The
State Council approved and forwarded Outline of the Eighth Five-Year Plan for the Cause of Disabled Persons in China in the same year. [10] 1990 witnessed the release of Interim Regulations on the Administration of Social Welfare Enterprises and Law of the People's Republic of China on the Protection of Disabled Persons. 1994 saw the promulgation of People with Disabilities Education Ordinance. In 1995 the Interim Provisions on the Administration of Employment Security Funds for The Disabled was issued. In 1996 the State Council endorsed Outline of the Ninth Five-Year Plan for the Cause of Disabled Persons in China. The State Council approved Opinions on Further Improving the Employment of Disabled Persons in 1999, endorsed Outline of the Tenth Five-Year Plan for the Cause of Disabled Persons in China and promulgated Basic Norms for Social Welfare Institutions for the Disabled in 2001. During this period, the focus of public service for the disabled has gradually shifted from their basic needs for survival to their rights such as rehabilitation, education and employment. The service mechanism in which the government, society, household and individuals participate in public service as the responsibility subjects has taken shape, leading to a strong social security system for the disabled. The basic public service for the disabled then was systematic, law-based and socialized, subverting the original landscape that is directly controlled by the government and interfered by administration branches. The emphasis of public service for the disabled also changed from adoption relief to labor welfare, and from basic subsistence security to social participation and integration. The disabled then, as equal individuals, were recognized and respected to a certain extent, and their basic, economic and service welfare were paid attention to. Their social rights and interests were well protected, thus significantly improving social welfare security.

The third stage refers to the period from 2006 to 2012, the transition period of public service for the disabled, represented by the launch of the second national sample survey of disabled persons. Given the essential role of people-oriented value on economic and social progress, China then highlighted the transformation of social policies. The fairness and justice of policies and the protection of people's livelihood rights were emphasized. Accordingly, public service for the disabled has heralded historic transformation and construction. The second national sample survey of disabled persons was launched in 2006 , contributing to the release of relevant laws and regulations on disabled persons and a series of policies. In 2007, China signed Convention on the Rights of Persons with Disabilities, adopted Regulations on the Employment of Persons with Disabilities, and formulated Measures for the Qualification of Welfare Enterprises. Opinions of the CPC Central Committee 
and the State Council on Promoting the Development of Undertakings for the Disabled was issued by the State Council in 2008. Law of the People's Republic of China on the Protection of Disabled Persons was amended and adopted at the second Session of the Standing Committee of the Eleventh National People's Congress. In 2010, the General Office of the State Council forwarded the Notice on Guiding Opinions on Accelerating the Construction of Social Security System and Service System for the Disabled. 2011 witnessed the implementation of emergency rehabilitation project for impoverished disabled children and the rehabilitation project of special lottery and public welfare fund for disabled persons. In 2012, the State Council passed the Regulations on Construction of Barrier-Free Environment, the China Disabled Persons' Federation formulated National Blindness Prevention and Treatment (2012-2015), and Opinions on Strengthening Cultural Construction of Disabled Persons. In view of the transformation from economic policy to social policy in this period, public service system for the disabled then was evolving into a service-oriented pattern that highlights people's livelihood rights, individual development and social integration. The mechanism of public service for the disabled, which involves various service and multilevel participation from diversified subjects by means of multi-channels, has emerged, integrating both "universal benefit" with "preferential benefit". Thanks to huge structural changes on the ethics, values and theory that support the public service for the disabled in China, state responsibility and civil rights caught attention, instead of socialist humanitarianism and ethics as usual.

The fourth stage is from 2013 to now. The convening of the 18th National Congress of the CPC ushered in a new stage of China's reform and development, and a new upsurge in the undertakings for the disabled, during which the public service for the disabled were greatly improved. As for social development, exclusively emphasis on economic growth has been replaced by the coordinated progress of society and economy. Unprecedented attention has also been paid to systematicness, integrity and synergy of social development. According to the third Plenary Session of the 18th CPC Central Committee: "All sources of social wealth should flow to the full, so that the fruits of development will be equally shared by all people." China's undertakings for the disabled also usher in the deepening of reform and optimization accordingly. In 2014, government work report of State Council proposed to "improve basic public service and disability prevention for the disabled". In the same year, China Disabled Persons' Federation issued Plan for Promotion of Special Education (2014-2016) and Guidelines on Promoting the Establishment of Living Subsidies for Disabled Persons with Difficulties and
Nursing Subsidy Systems for Severely Disabled Persons. The State Council issued Opinions of the State Council on Accelerating the Well-off Process of Disabled People in 2015 and Outline for Accelerating the Welloff Process of Disabled People During the 13th FiveYear Period in 2016. 2016 witnessed the release of the National Action Plan for Disability Prevention (20162020), and 2017 saw the promulgation and implementation of the Regulations on Disability Prevention and Rehabilitation. With the development of the "two systems (social security system and service system for the disabled)" as the core, public service for the disabled have been improved, guaranteeing that the disabled benefit from reform and development in a more equitable manner. People with disabilities have raised their income, improved their quality of life and sustained progress in integrated development, enabling them to live and work in peace and contentment, and lead richer, happier and more dignified lives.

According to the stages of public service for the disabled since the founding of People's Republic of China, especially the three stages after the reform and opening up, the progress of public service for the disabled in China is closely related to economic growth. Just as the saying goes, economic base determines the superstructure, only when the economy develops will the social ideology change accordingly. Deng Pufang once recalled, "the CPC and the government has made huge efforts for the disabled after the founding of People's Republic of China..., which supports undertaking for the disabled. Every time I look back, I am very excited. We are awed by the pioneering work of predecessors. However, it was not until after the third Plenary Session of the eleventh Central Committee that the cause of the disabled in China was fully started", "At that time, inspired by the idea of humanitarianism that emerged and the insight of 'equality, participation and sharing' among international community, the majority of disabled people in China under the leadership of the Party and the government rose up and made constant efforts, opening a new chapter for the cause of disabled people. First came the resumption of work of China Association for the Blind and Deaf, then the establishment of China Foundation for Disabled Person, and finally the launch of China Disabled Persons' Federation. Among them, the last was the biggest achievement and symbol of the cause of the disabled in that period". [11]

\section{THEORETICAL PATH OF PUBLIC SERVICE FOR THE DISABLED WITH CHINESE CHARACTERISTICS}

The past 40-odd years of reform and opening up have proved that only by adhering to the path of socialism with Chinese characteristics can national prosperity and people's happiness be achieved. The 
same is true for the cause of disabled persons in China. Current situation of China and its disabled persons must be taken amount when choosing suitable path. [12] Man serves as both an end and a means. The free and comprehensive development of the disabled is closely associated to economic and social growth. Social development cannot be achieved without human. The aim of social development lies in human, but not social development. Real person serves as the historical and logical starting point of social development, as well as its purpose and end-result. Social development can only highlight its own value if it centers on people. Deng Pufang first and indirectly proposed the notion of the undertaking of the disabled with Chinese characteristics on his report entitled "Hold High the Great Banner of Socialism with Chinese Characteristics and Strive to Speed up the All-round Development of the Undertaking for the Disabled", delivered at the fifth National Congress of China Disabled Persons' Federation in November 2008. Aimed at building socialism with Chinese characteristics, the report elucidated the development of the undertaking of the disabled, and makes it clear that "the cause of the disabled in China has explored a path of healthy and sustainable development suitable for national conditions and with characteristics." "Since reform and opening up, China has undergone profound changes in society and landscape, and vitality has been injected into socialism with Chinese characteristics. As great era prompts huge achievements, the undertaking for the disabled has grasped the tailwind of spectacular reform and opening up, ushering in a new spring." Despite the absence of direct mention on "undertaking of the disabled with Chinese characteristics" in the report, the cause of the disabled is elucidated as a branch of the cause of socialism with Chinese characteristics. Since then, the term "undertaking of the disabled with Chinese characteristics" has come into people's sight. Basic public service for the disabled, an integral of the undertaking for the disabled, naturally features "Chinese characteristics".

\section{ORGANIZATIONAL PATH OF PUBLIC SERVICE FOR THE DISABLED WITH CHINESE CHARACTERISTICS}

The evolution of organizations concerning the disabled in China reveals that existing organizations mainly include disabled persons' federations at all levels and disabled persons' associations, which are based on disabled persons' federations and founded by disabled persons of varying category. Such organizations, social organizations integrating the functions of "representative, service and management", enjoy strong governmental color in terms of its original intention and evolution. In terms of organizational systems, these organizations are built from the top down. Following the leadership of the CPC Central
Committee and State Council, China Disabled Persons' Federation helps local governments at all levels to establish local disabled persons' federations in accordance with administrative divisions. Opinions on the Formation of Local Disabled Persons' Federations adopted at the first enlarged session of the first Executive Council of China Disabled Persons Federation clearly took that the formation of local disabled persons' federations shall be subject to the leadership of local governments and disabled persons federations at higher levels. Established by China Disabled Persons' Federation and civil affairs departments from top to bottom, the disabled persons' associations at all levels were born with a strong administrative color. As for the evolution of function orientation, disabled persons' federation has actually assumed the governmental functions of serving the disabled. The mission and slogan of China Foundation for Disabled Persons, the predecessor of China Disabled Persons' Federation, is to promote humanity, contribute love, and serve the disabled heart and soul. As regards organizational nature, it is a nationwide social welfare organization approved by the Chinese government, serving the disabled in the spirit of patriotism and socialist humanitarianism. According to Opinions on the Formation of Local Disabled Persons' Federations, the State Council stipulates that "China Disabled Persons' Federation shall share the treatment of general administration, be managed by Ministry of Civil Affairs, keep a separate account in the national plan and establish business relations with all departments under State Council and all provinces, autonomous regions and municipalities directly under the central government", and "disabled persons' federation is under the administration of the government. The chairman shall be recommended by the presidium of the federation and submitted to the government at the corresponding level for examination and approval and go through the formal appointment procedures". In terms of staffing, the full-time staff of China Disabled Persons' Federation belongs to the state administrative establishment, while the staff of directly affiliated institutions belong to the establishment of state public institutions. The This organ shall enjoy the treatment at the level of the general administration of State Council and shall have corresponding functions and limits of authority. The ministry (department) established by the organ shall be bureau-level organizations. As for functions, China Disabled Persons' Federation passes on complaints and insight of the disabled to the Party and the government, participates in and assists the government in formulating guidelines and plans for disabled persons, and adopts laws and policies to solve common problems afflicting disabled persons. [14] Since its birth disabled persons' federation has served as both an official and civil organization. It is officially defined as "an social organization exempt from registration", with 
corresponding administrative levels and party and government establishment. It is not only China's representative and administrative body in the field of disabled people, but also a social group responsible for the supply of public goods. The introduction of China Disabled Persons' Federation by State Council reveals that the administrative function of the federation outweighs its role as social organization on behalf of the disabled. China Disabled Persons' Federation, an organization for the disabled approved by State Council and recognized by laws, serves as organization by the disabled themselves, social welfare organization, and administrative body, and enjoys the functions of "representative, service and management": that is, to represent the common interests of the disabled and safeguard their lawful rights and interests; to carry out various operations and activities that directly serve the disabled; and to undertake some administrative functions entrusted by the government, and to develop and manage undertakings for the disabled." [15] China Disabled Persons' Federation, as the competent administrative department of non-governmental organizations for disabled persons, administers other non-governmental organizations for disabled persons. In China, it shares administrative rank as government department headed by a Party committee at the same level. Therefore, it is a special unit which is free from registration and supervisor and has the power to "manage others", which breaks out of the "dual registration management system". [16] The administrative nature of disabled persons' federation, the main body of public service for the disabled, reflects that basic public service for the disabled in China bears distinct Chinese characteristics.

\section{INSTITUTIONAL PATH OF PUBLIC SERVICE FOR THE DISABLED WITH CHINESE CHARACTERISTICS}

The system that embodies "good governance" should finally be fixed in the form of law. Study on China's laws and regulations on the disabled contributes to better understand the institutional path of public service for the disabled with Chinese characteristics. The disabled is mentioned on Constitution of the People's Republic of China. Law of the People's Republic of China on the Protection of Disabled Persons, China's first special law for disabled persons, "is an essential law that enables disabled persons to participate in social life on the equal footing as normal people". [17] People with Disabilities Education Ordinance is issued in 1994 and revised in 2017. Regulations on the Employment of Persons with Disabilities comes into force in 2007. Opinions of the CPC Central Committee and the State Council on Promoting the Development of Undertakings for the Disabled is released in 2008. Opinions of Publicity Department of the CPC Central Committee and other
Departments on Strengthening Cultural Development of Disabled Persons and Regulations on Construction of Barrier-Free Environment are put into effect in 2012. Regulations on Disability Prevention and Rehabilitation comes into force in 2017. All these proves that the state has made clear the main content of basic public service for the disabled by issuing regulations or opinions.

As for legal forms, China has established a system of laws and regulations with Constitution of People's Republic of China as the core and Law of the People's Republic of China on the Protection of Disabled Persons as basis, including relevant laws, regulations, rules and preferential support provisions to protect the rights and interests of disabled persons and develop undertakings for disabled persons. Laws with specific provisions on the protection of the rights of persons with disabilities amount to 60-odd, covering People with Disabilities Education Ordinance, Regulations on Disability Prevention and Rehabilitation, Regulations on the Employment of Persons with Disabilities and Regulations on Construction of Barrier-Free Environment promulgated by State Council, and the measures for the implementation of the protection of the disabled formulated by all provinces, autonomous regions and municipalities directly under the central government. As regards the implementation of the law, annual inspections and studies on the implementation of Law of the People's Republic of China on the Protection of Disabled Persons are conducted by National People's Congress (NPC), National People's Political Consultative Conference (CPPCC) and local people's congresses and CPPCC committees at all levels. Special inspections on the rehabilitation, employment and poverty alleviation of the disabled are conducted annually by governments at all levels and relevant departments. In addition, people's courts at all levels, legal services and legal aid agencies provide a large number of judicial assistance, legal services and legal aid for the disabled. As a result, the implementation of relevant laws and regulations concerning disabled persons have been greatly promoted. At the macro level, China integrates the practical needs of disabled people into the overall planning in accordance with the social structure, while legal policies focus on and stipulate the social support for disabled people, and involve disabled people's organizations in plans and programs involving disabled people or in all decision-making processes affecting their economic and social status. China undertakes due responsibilities and obligations for the development of the disabled, and actively guides and encourages organizations, societies and citizens to shoulder auxiliary responsibilities for providing service, activities and information, which demonstrates Chinese characteristics and the spirit of responsibility of a major country. At the micro level, legal policies helps to 
eliminate environmental discrimination against persons with disabilities. Special laws on disability matters helps to incorporate disability matters in legislation on specific subjects and documents interpreting existing legislation, thus establishing formal legal complaint mechanism to protect the interests of persons with disabilities. In this way, the disabled, who have not received social support for a long time, can be guaranteed survival and development, and have access to such survival and development resources as medical care, rehabilitation, disability prevention, education and employment through legal means, so as to equally enjoy basic public service and get rid of the dilemma of survival and development caused by lack of competitiveness. Social prejudice against the disabled can be eliminated from the institutional level, fully guaranteeing their equal access in social life, and fully reflecting the idea of "people-centered".

\section{CONCLUSION}

China's basic public service for the disabled, an integral of its undertakings for the disabled, has accumulated much experience and achieved success through years of development. Relevant laws and regulations have basically taken shape, and work for the disabled has been deepened and expanded. The socialist humanitarian spirit of respecting and caring for the disabled has also gained greater popularity. What's more, the undertaking of the disabled has been widely recognized by the society, blazing a path of healthy and sustainable development suitable for China's national conditions and with Chinese characteristics, and evolving into a comprehensive social cause covering broad fields and with Chinese characteristics. A retrospect on the cause of the disabled in China over the past 70 years shows that the living and development conditions of the disabled have been continuously and significantly improved from the perspective of the majority of disabled people. As for the development of undertaking for the disabled, thanks to years of practice and exploration, a path with Chinese characteristics, covering guiding ideology, leadership system, operating mechanism and development mode, has been formed. As for the overall development of the country, the disabled serves as not only the beneficiaries of the socialist modernization drive, but also participants and contributors. China's work on the disabled provides China's experience in solving the issue of the disabled with a large population in developing countries. In conclusion, China's public service for the disabled must follows people-centered philosophy, establish and improve institutions and mechanisms, and builds its development path featuring Chinese characteristics, Chinese style and Chinese model.

\section{References}

[1] Jiang Zemin. Song of Self-Strengthening (Preface) [M]. Beijing: Huaxia Publishing House, 1993: 05-06. (in Chinese)

[2] Baidu Encyclopedia: Gifts [EB/OL].[2019-03-24]. (in Chinese) https://baike.baidu.com/item/\%E7\%A4\%BC\%E8\%BF\%90/591 3242 ?fr= aladdin

[3] Interim Regulations on Preferential Treatment and Compensation of Revolutionary Disabled Army men [J] Gazette of the People's Government of Jiangxi Province, 1950(12): 58-61. (in Chinese)

[4] Provisional Regulations on Compensation for Casualties of Revolutionary Personnel [J]. Gazette of the People's Government of Jiangxi Province, 1950(12): 62-63. (in Chinese)

[5] Interim Regulations on Compensation for Injuries and Casualties of Militia and Civil Workers [J]. Gazette of the People's Government of Jiangxi Province, 1950(12): 64. (in Chinese)

[6] Cheng Haijun, Chen Xiaoli. Study on the CPC's Ideology of Social Welfare during the Period of Planned Economy [J]. Journal of Executive Leadership Academy Pudong, 2011(3): 102-108. (in Chinese)

[7] China Statistical Yearbook on the Work for Persons with Disabilities 1949-1993 [M]. Beijing: Huaxia Publishing House, 1996. (in Chinese)

[8] China Statistical Yearbook on the Work for Persons with Disabilities 1949-1993 [M]. Beijing: Huaxia Publishing House, 1996. (in Chinese)

[9] China Statistical Yearbook on the Work for Persons with Disabilities 1949-1993 [M]. Beijing: Huaxia Publishing House, 1996. (in Chinese)

[10] China Statistical Yearbook on the Work for Persons with Disabilities 1949-1993 [M]. Beijing: Huaxia Publishing House, 1996. (in Chinese)

[11] Ji Gang, Shou Tian. The cause of the disabled is essential for reform and opening up: Summary of the Symposium of Disability in China Magazine to commemorate the 30th anniversary of reform and opening up [J]. Disability in China, 2008(11): 9-11. (in Chinese)

[12] Qiu Guanjian, An Zhimin. Roads, theories, systems-the construction of a system for the development of the cause of the disabled with Chinese characteristics [J]. Theory Monthly, 2015(3): 148-152. (in Chinese)

[13] Deng Pufang. A work report entitled "Hold high the great banner of socialism with Chinese characteristics and strive to speed up the all-round development of the cause for the disabled" delivered to the fifth National Congress of the China Disabled Persons' Federation on behalf of the fourth Chairman's Delegation. (in Chinese)

[14] Ge Zhongming, Yang Yan. Analysis of the construction of the organization system for persons with disabilities under the background of the welfare system reform. [R]. Conference on Social Welfare Policy and Service for the Disabled \& the 6th Forum for the Disability Research in China. (in Chinese)

[15] China Disabled Persons' Federation [EB/OL]. (2008-11-14). [2020-06-13]. (in Chinese) http://www.gov.cn:8080/test/200811/14/ content_1148726.htm

[16] Qin Qinzeng, De Jin. Relationship among the Chinese Government, the CDPF and the Civil Organizations for the Disabled [J]. Journal of Social Sciences, 2014(4): 90-98. (in Chinese)

[17] Cheng Chuanwei, Lu Zheng. Equality: Standing on the Same Horizon - Written when People with disabilities act of the Peoples Republic of China was promulgated [J]. Shanghai Municipal People's Congress, 1991 (2): 14-16. (in Chinese) 